\title{
Interim Status Report On The Design Of The Gas-Cooled Fast Reactor (GFR)
}

\author{
Kevan D. Weaver
}

January 2005 


\title{
Interim Status Report On The Design Of The Gas-Cooled Fast Reactor (GFR)
}

\author{
Kevan D. Weaver \\ January 2005 \\ Idaho National Engineering and Environmental Laboratory \\ Idaho Falls, Idaho 83415 \\ Prepared for the \\ U.S. Department of Energy \\ Assistant Secretary \\ Office of Nuclear Energy, Science, and Technology \\ Under DOE-NE Idaho Operations Office \\ Contract DE-AC07-05ID14517
}




\section{Abstract}

Current research and development on the Gas-Cooled Fast Reactor (GFR) has focused on the design of safety systems that will remove the decay heat during accident conditions, ion irradiations of candidate ceramic materials, joining studies of oxide dispersion strengthened alloys; and within the Advanced Fuel Cycle Initiative (AFCI) the fabrication of carbide fuels and ceramic fuel matrix materials, development of non-halide precursor low density and high density ceramic coatings, and neutron irradiation of candidate ceramic fuel matrix and metallic materials. The vast majority of this work has focused on the reference design for the GFR: a helium-cooled, direct power conversion system that will operate with on outlet temperature of $850^{\circ} \mathrm{C}$ at $7 \mathrm{MPa}$.

In addition to the work being performed in the United States, seven international partners under the Generation IV International Forum (GIF) have identified their interest in participating in research related to the development of the GFR. These are Euratom (European Commission), France, Japan, South Africa, South Korea, Switzerland, and the United Kingdom. Of these, Euratom (including the United Kingdom), France, and Japan have active research activities with respect to the GFR. The research includes GFR design and safety, and fuels/in-core materials/fuel cycle projects.

This report outlines the current design status of the GFR, and includes work done in the areas mentioned above. 


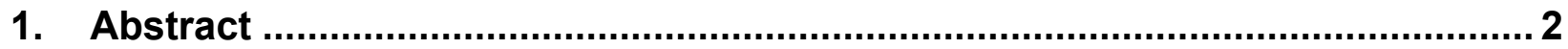

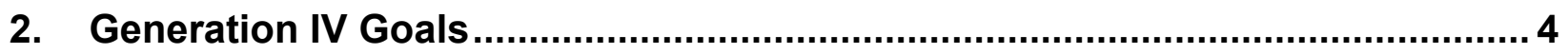

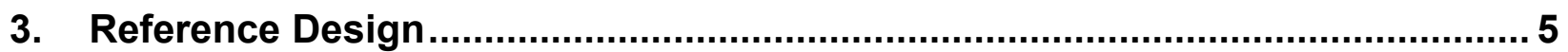

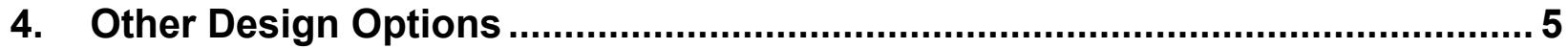

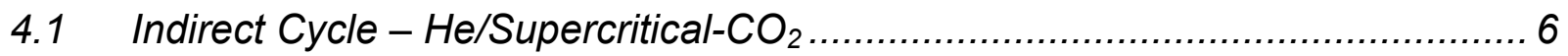

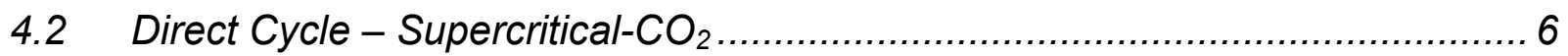

5. Current Status of the Reference Design .......................................................... 7

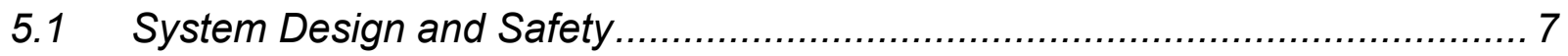

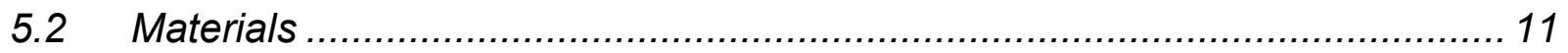

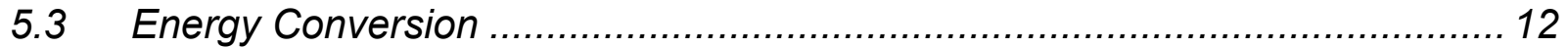

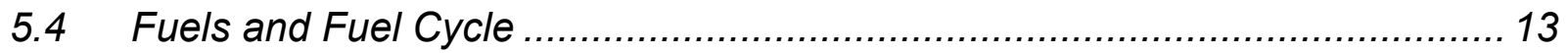

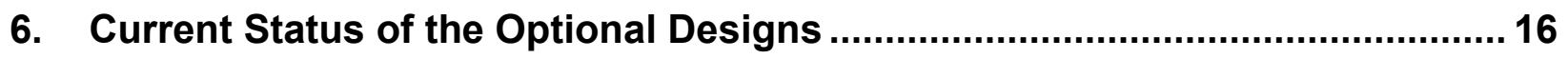

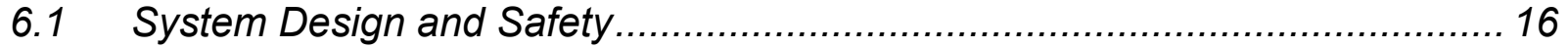

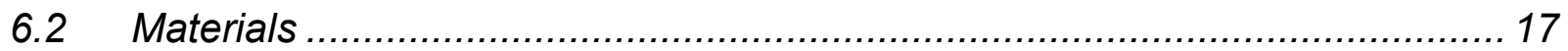

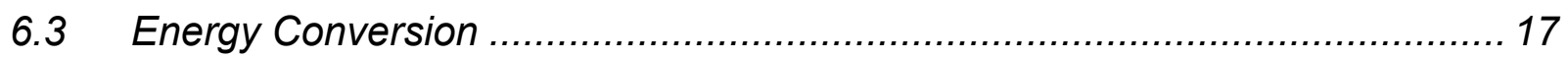

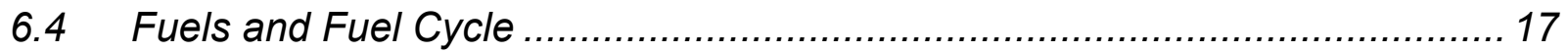

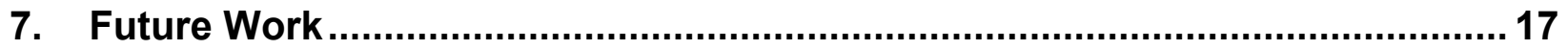

7.1 Path Forward for a Down Selection .......................................................... 17 


\section{Generation IV Goals}

During the Generation IV technology roadmap, goals were established for next generation nuclear energy systems. As stated in the roadmap, the goals have three purposes: 1) they serve as the basis for developing criteria to assess and compare the systems in the technology roadmap; 2) they are challenging and stimulate the search for innovative nuclear energy systems - both fuel cycles and reactor technologies; and 3) they will serve to motivate and guide the R\&D on Generation IV systems as collaborative efforts get underway.

The eight goals for Generation IV were defined in four broad areas of 1) sustainability, 2) economics, 3) safety and reliability, and 4) proliferation resistance and physical protection. The sustainability goals focused on fuel utilization and waste management, and are given in more detail here:

Sustainability-1 Generation IV nuclear energy systems will provide sustainable energy generation that meets clean air objectives and promotes long-term availability of systems and effective fuel utilization for worldwide energy production.

Sustainability-2 Generation IV nuclear energy systems will minimize and manage their nuclear waste and notably reduce the long-term stewardship burden, thereby improving protection for the public health and the environment.

The economics goals focused on competitive life cycle and energy production costs, and financial risk. The details of these goals are:

Economics-1 Generation IV nuclear energy systems will have a clear life cycle cost advantage over other energy sources.

Economics-2 Generation IV nuclear energy systems will have a level of financial risk comparable to other energy projects.

The safety and reliability goals focused on safe and reliable operation, improved accident management and minimization of consequences, investment protection, and essentially eliminating the technical need for off-site emergency response. The details are:

Safety and Reliability-1 Generation IV nuclear energy systems operations will excel in safety and reliability.

Safety and Reliability-2 Generation IV nuclear energy systems will have a very low likelihood and degree of reactor core damage.

Safety and Reliability-3 Generation IV nuclear energy systems will eliminate the need for offsite emergency response.

The proliferation resistance and physical protection goal focused on controlling and securing nuclear material and nuclear facilities. The goal is:

Proliferation Resistance and Physical Protection-1 Generation IV nuclear energy systems will increase the assurance that they are a very unattractive and the least desirable route for diversion or theft of weapons-usable materials, and provide increased physical protection against acts of terrorism.

Each of the Generation IV systems was chosen based on their ability to achieve these goals. However, these goals are often competitive one with another, as is the case for the GFR. The 
GFR can maintain a high level of safety for low values of the power density (on the order of those used for the VHTR - 8kW/1), relying solely on conductive and radiative heat transfer during a severe transient (such as loss of coolant combined with loss of offsite power), and yet maintain low fuel temperatures. Unfortunately, the first core fuel cycle costs for fully passive designs of the GFR can be equal to the capital costs of the reactor. Clearly the economics of this design outweigh the safety case, even though true passive safety is achieved. In this case, a balance must be struck between safety and economics.

Other examples can be given (e.g., the sustainability of low versus high conversion ratio cores, the economics of full actinide recycle versus the proliferation risk, etc.), but will not be enumerated here.

\section{Reference Design}

The reference GFR system features a fast-spectrum, heliumcooled reactor and closed fuel cycle (see Figure 1). This was chosen as the reference design due to its close relationship with the VHTR, and thus its ability to utilize as much VHTR material and balance-of-plant technology as possible. Like thermal-spectrum helium-cooled reactors such as the GasTurbine Modular Helium Reactor (GT-MHR) and the Pebble Bed Modular Reactor (PBMR), the high outlet temperature of the helium coolant makes it possible to deliver electricity, hydrogen, or process heat with high conversion efficiency. The GFR reference design will utilize a direct-cycle helium turbine for electricity (42\% efficiency at $850^{\circ} \mathrm{C}$ ), and process heat for thermochemical production of hydrogen.

In order to withstand the high temperatures within the reactor, special consideration must be given to the fuel and in-core materials. The reference fuel matrix for the Generation IV GFR is a cercer dispersion fuel in a refractory ceramic matrix, based on a balance between conductivity and high temperature capability. These fuels will be mixed carbide or nitrides.

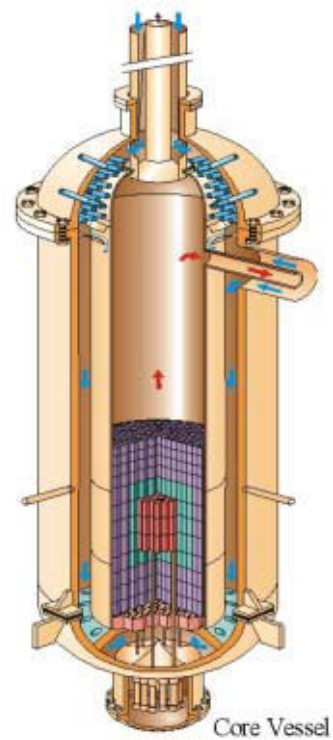

Figure 1. Schematic of the GFR vessel and core configuration for block/plate core.

\section{Other Design Options}

Other design options are being considered that will fulfill the Gen IV goals, but do not necessarily preserve the close relationship with the VHTR. However, at this point, these lower temperature options will not require any additional work on fuels and materials. As such, it is important that these designs are studied and kept as open options for the GFR. Not detailed in the subsequent sections is the indirect, $\mathrm{CO}_{2}$ /steam cycle that is being researched by Japan and the United Kingdom. Only research being performed in the U.S. is mentioned. 


\subsection{Indirect Cycle - He/Supercritical- $\mathrm{CO}_{2}$}

One of the optional designs is also a helium-cooled system, but utilizes an indirect Brayton cycle for power conversion. The secondary system of the alternate design utilizes supercritical $\mathrm{CO}_{2}$ $\left(\mathrm{S}-\mathrm{CO}_{2}\right)$ at $550^{\circ} \mathrm{C}$ and $20 \mathrm{MPa}$ (see Figure 2). This allows for more modest outlet temperatures in the primary circuit $\left(\sim 600-650^{\circ} \mathrm{C}\right)$, reducing the strict fuel, fuel matrix, and material requirements as compared to the direct cycle, while maintaining high thermal efficiency $(\sim$ $42 \%)$.

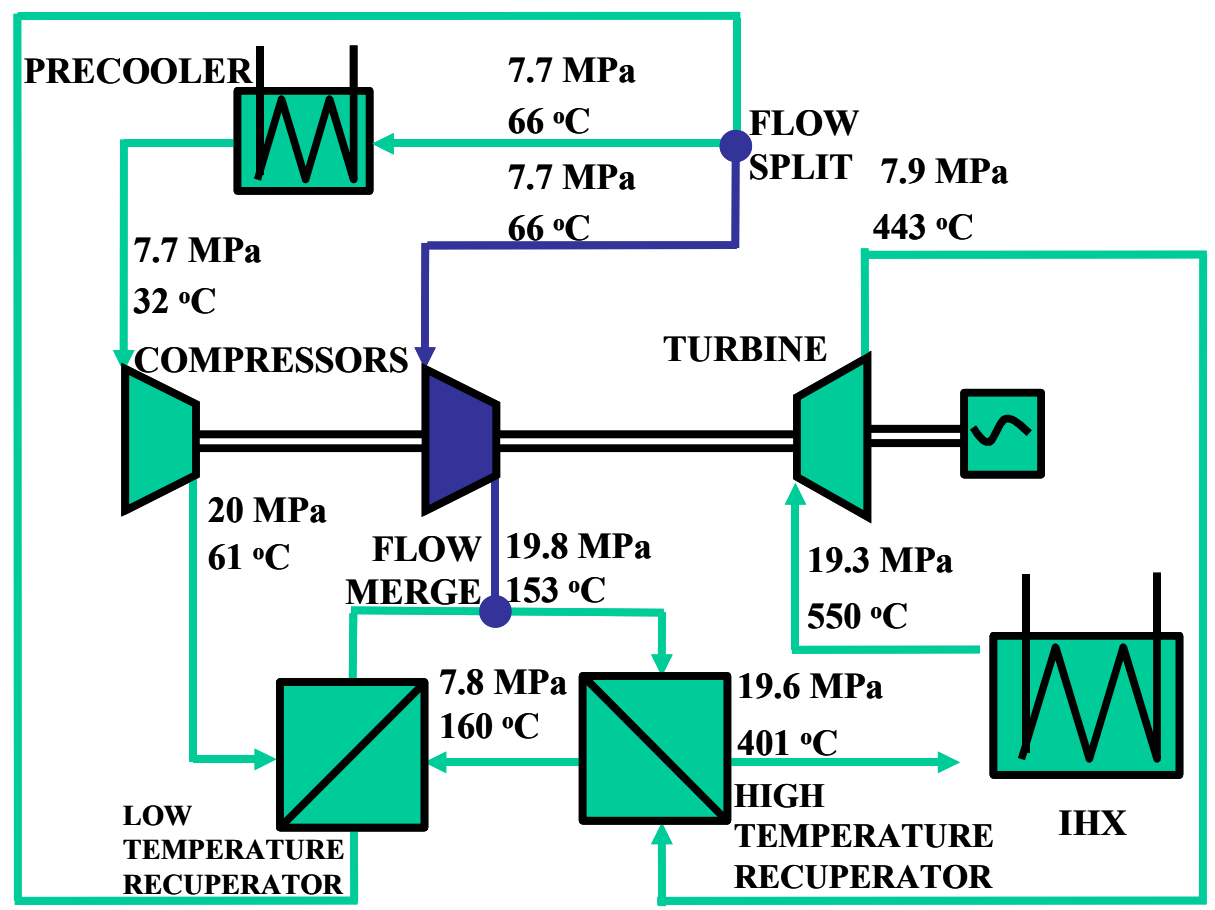

Figure 2. Schematic of the indirect $\mathrm{S}-\mathrm{CO}_{2}$ recompression cycle.

\subsection{Direct Cycle - Supercritical- $\mathrm{CO}_{2}$}

Another optional design is a $\mathrm{S}-\mathrm{CO}_{2}$ cooled $\left(550^{\circ} \mathrm{C}\right.$ outlet and $\left.20 \mathrm{MPa}\right)$, direct Brayton cycle system. The main advantage of this optional design is the modest outlet temperature in the primary circuit, while maintaining high thermal efficiency $(\sim 45 \%)$. Again, the modest outlet temperature (comparable to sodium-cooled reactors) reduces the requirements on fuel, fuel matrix/cladding, and materials, and even allows for the use of more standard metal alloys within the core. This has the potential of significantly reducing the fuel matrix/cladding development costs as compared to the reference design, and reducing the overall capital costs due to the small size of the turbomachinery and other system components. The power conversion cycle is equivalent to that shown in Figure 2, where the IHX would be replaced by the reactor and reactor pressure vessel. 


\section{Current Status of the Reference Design}

\subsection{System Design and Safety}

Current design studies are focused on two power options, 600MWt and 2400MWt, utilizing a direct cycle with helium at $850^{\circ} \mathrm{C}$ outlet temperature, and $7 \mathrm{MPa}$. The advantages to each of these power options are given below:

- $600 \mathrm{MWt}$

○ Enables "modular" design (i.e., small vessel, small core, etc., that can be transported to site)

- Can utilize the 300 MWe VHTR balance-of-plant (BOP) development, thus minimizing R\&D costs

- $2400 \mathrm{MWt}$

○ Better neutron economy, thus reducing the heavy metal inventory requirement

- More adaptable to large base load operation

- Can utilize current VHTR reactor pressure vessel size/technology (i.e., core will fit in current VHTR RPV)

Additional parameters for the reference design are given in Table 1, below.

Table 1. Parameters for the GFR reference design.

\begin{tabular}{|l|c|}
\hline \multicolumn{1}{|c|}{ System Parameter } & Reference Value \\
\hline Power level & $600 \mathrm{MWth}$ \\
Net efficiency & $42 \%$ \\
Coolant pressure & $70 \mathrm{bar}$ \\
Outlet coolant temperature & $850^{\circ} \mathrm{C}$ \\
Inlet coolant temperature & $490^{\circ} \mathrm{C}$ \\
Nominal flow \& velocity & $330 \mathrm{~kg} / \mathrm{s} \& 40 \mathrm{~m} / \mathrm{s}$ \\
Core volume & $11 \mathrm{~m}^{3}(\mathrm{H} / \mathrm{D} \sim 1.7 / 2.9 \mathrm{~m})$ \\
Core pressure drop & $\sim 0.4 \mathrm{bar}$ \\
Volume fractions of Fuel/Gas/SiC & $50 / 40 / 10 \%$ \\
Average power density & $55 \mathrm{MW} / \mathrm{m}^{3}$ \\
Reference fuel composition & $U P u C / S i \mathrm{C}(50 / 50 \%)$ \\
Breeding/Burning performances & fissile breakeven \\
In core heavy metal inventory & 30 tonnes \\
Fissile (TRU) enrichment & $\sim 20 \mathrm{wt} \%$ \\
Fuel management & multi-recycling \\
Fuel residence time & $3 \times 829$ efpd \\
Discharge burnup ; damage & $\sim 5$ at\%; $60 \mathrm{dpa}$ \\
Primary vessel diameter & $<7 \mathrm{~m}$ \\
\hline
\end{tabular}

The safety system optimization part of the effort has concentrated on low-pressure drop core designs for the large $2400 \mathrm{MWt}$ plant option (economies-of-scale), while the transient analysis part of the effort has concentrated on the anticipated transient without scram (ATWS) response of the modular 600MWt plant. 
Several core designs exist, and are presently being assessed using several performance measures, including safety characteristics that are addressed here. The GFR differs from the thermal gas reactor in several respects important for safety behavior. Past studies of the thermal gas reactor operating under a direct cycle have shown that safety for unprotected accidents is assured largely as a result of a very low power density, and a combination of a high temperature to fuel failure, large Doppler feedback, and large thermal inertia. By contrast, the power density in the GFR is an order of magnitude greater, the coolant density coefficient adds reactivity during depressurization accidents (which has no counterpart in the thermal core), and there are no large blocks of graphite (thermal inertia). These fundamental differences give the reactivity feedbacks a more prominent role in the safety of the fast reactor compared to the thermal gas reactor. As a consequence, an important design objective is to engineer the fast reactor core to have sufficient inherent negative reactivity feedback that core power safely adjusts to the available heat sink.

While a core layout and balance of plant exist for the $600 \mathrm{MWt}$ design studied, the plant control system has not yet been designed. In addition, only preliminary designs for the $2400 \mathrm{MWt}$ gascooled fast reactor have been evaluated. Note that the important aspect of the design is the removal of decay heat under depressurized conditions. Because the current fast reactor design is to have a power density of 50-100 W/cc, a flowing reactor coolant must remove most of the decay heat. A requirement that the reactor be passively safe during a total loss of power at the reactor site necessitates the employment of natural convection. Past studies have shown that natural convection is not effective at atmospheric pressure. Therefore, a guard containment that encloses the primary vessel is used to preserve a backpressure that maintains a high coolant density. During a total loss of site power, the leakage around the seals of the primary system will allow the reactor pressure to slowly decrease toward atmospheric pressure if it were not for the secondary (or guard) containment. The design goal is to limit the pressure that the guard containment must maintain, since the cost of the guard containment increases with its required pressure capability.

The pressure requirement of the guard containment is determined by the coolant density that permits sufficient natural convection through the reactor core during the prescribed off normal or upset conditions. In a direct cycle reactor plant, the hydraulic resistance through the power conversion unit would essentially preclude natural convection flow. Therefore, one or more additional emergency cooling loops, that are isolated from the primary loop by check valves during normal operation, will be needed. Each of these loops will have an emergency heat exchanger (EHX), probably of the Heatric ${ }^{\circledR}$ printed circuit heat exchanger (PCHE) type, which will use natural convection to reject heat to the environment. The most significant hydraulic resistances in these loops are typically in the reactor core and the EHXs. Larger core resistances will require greater guard containment pressure capabilities. Therefore, the focus of the current effort is to design reactor cores with an absolute minimum hydraulic resistance.

Figure 3 shows the schematic of an EHX for the GFR. 


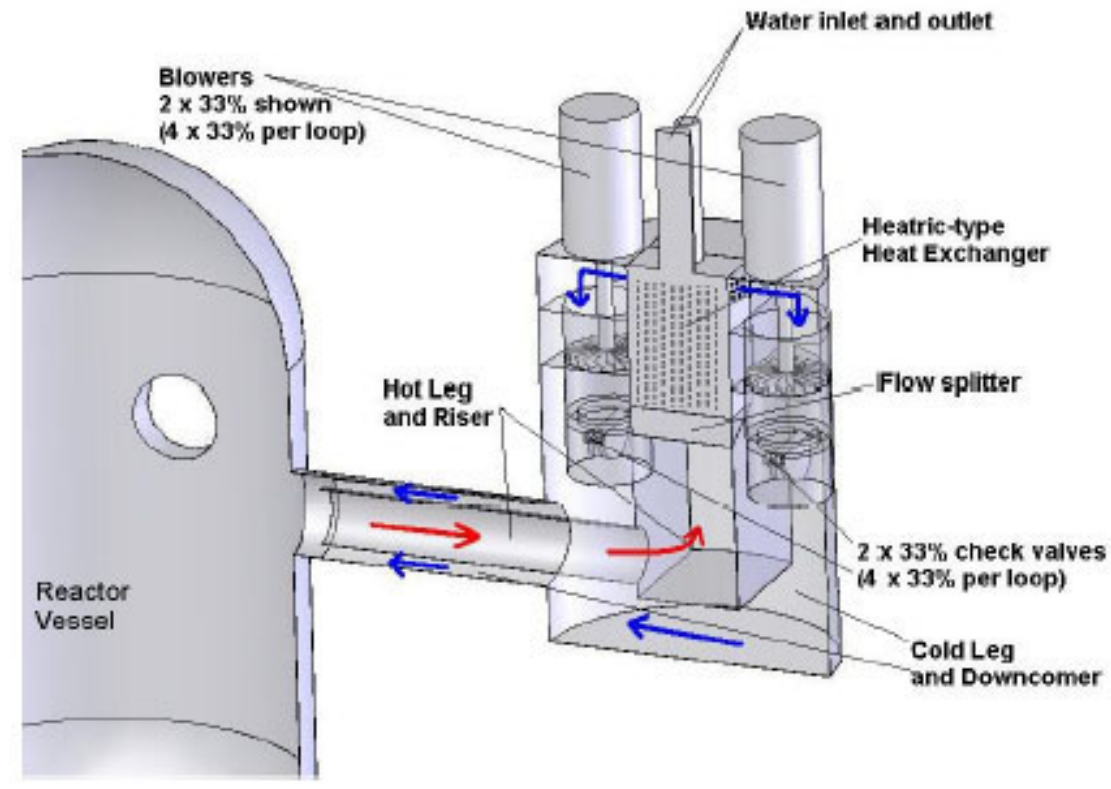

Figure 3. Current EHX design for decay heat removal (DHR) in the GFR

Current designs are focused on both the block/plate type core, and on a ceramic clad pin with solid solution fuel. These particular designs allow for the low pressure drops necessary for minimal backpressures. The core layout for the 600MWt design can be seen in Figure 4.
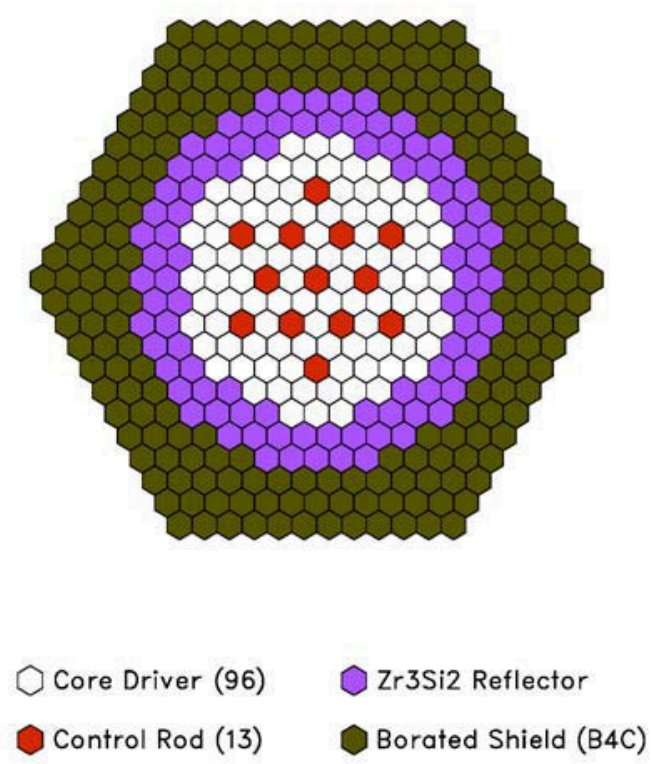

Figure 4. Core layout for the $600 \mathrm{MWt}$ GFR.

The core layout for the 2400MWt can be seen in Figure 5. 


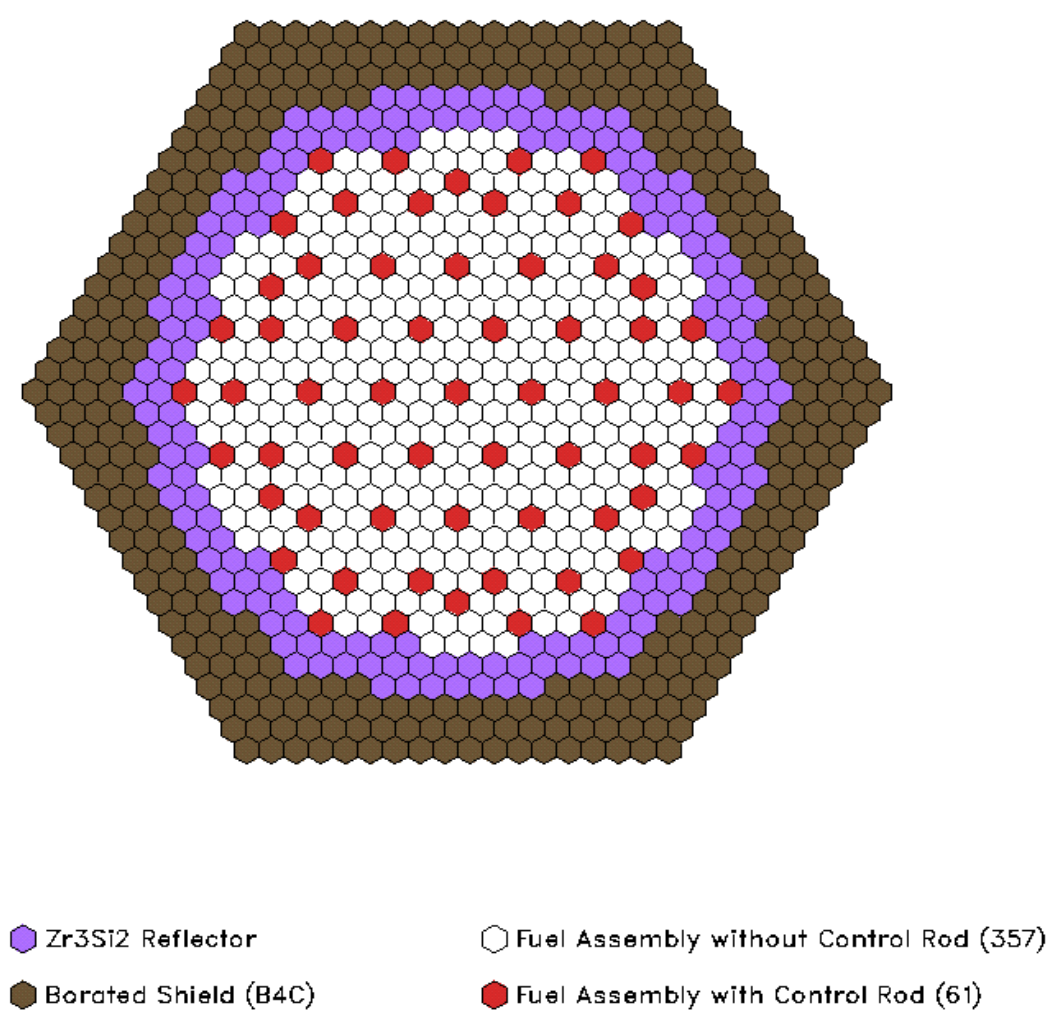

Figure 5. Core layout for the $2400 \mathrm{MWt}$ GFR.

Both the pin core and block/plate core follow the layouts in Figures 4 and 5 above.

The fast reactor experience with the LMR and ALMR indicated a need for a spent fuel cool down approach different from the approach taken by the LWRs. This was due to the significantly higher core power densities of the LMRs. The same issue was faced by the earlier generation of gas cooled fast reactors, the GCFRs. The LMRs selected in-tank spent fuel storage where a fuel storage basket was located in the primary tank below the sodium level. The primary coolant sodium thus provided a means for both cooling the fresh and partially burnt fuel assemblies in the active core region, as well as the spent fuel in the storage basket. After a sufficient cooling period, the spent fuel assemblies were then removed from the storage basket, pulled out of the primary system, and entered the fuel transfer system to be eventually relocated into the spent fuel storage system. The GA GCFR of twenty-five years ago opted not to select the in-vessel storage system. With the GCFR core power densities being lower than the LMR core power densities, the GCFR spent fuel removal approach was more similar to that used for the LWR. The spent fuel assembly was removed from the core upon discharge and transferred to storage locations in the spent fuel pool where it was stored under water during the cooling period before eventual disposal off-site. However, since the GCFR assembly power densities were still significantly higher than those of the LWRs, forced cooling was provided during every step. This ex-vessel spent fuel storage option was retained for the GFR. This allows for the reduction of heat loads within the vessel, which lowers the challenge for cooling requirements, both active and passive during accidents, and also for a significant reduction in vessel diameter. The vessel diameter shown in Figure 6 for a proposed 600MWt plant design is significantly smaller than 
that for the 600MWt GT-MHR. This lowers the capital cost and allows for a smaller guard containment. Figure 6 shows an elevation view of the vessel, the PCU and one of the decay heat removal loops. Also shown are the spent fuel pool and the fresh fuel pit. The fuel handling machines, spent fuel transfer cask and bridge crane are included. The dimensions are indicated in meters. Since the containment function is to be performed by the guard containment, the building will be a confinement building. The layout shows a totally above-grade configuration for the confinement building. The spent and fresh fuel have, therefore, to be moved from the refueling floor to the ground level to be transported on and off-site. The next design iterations may well have a partially below grade design. Not only would this simplify the fuel transfer, but it also could mitigate the seismic response of the structures. In this ex-vessel storage option, it can be seen from Figure 6 that the vessel is narrow and elongated. Partial-below grade placement could be beneficial.

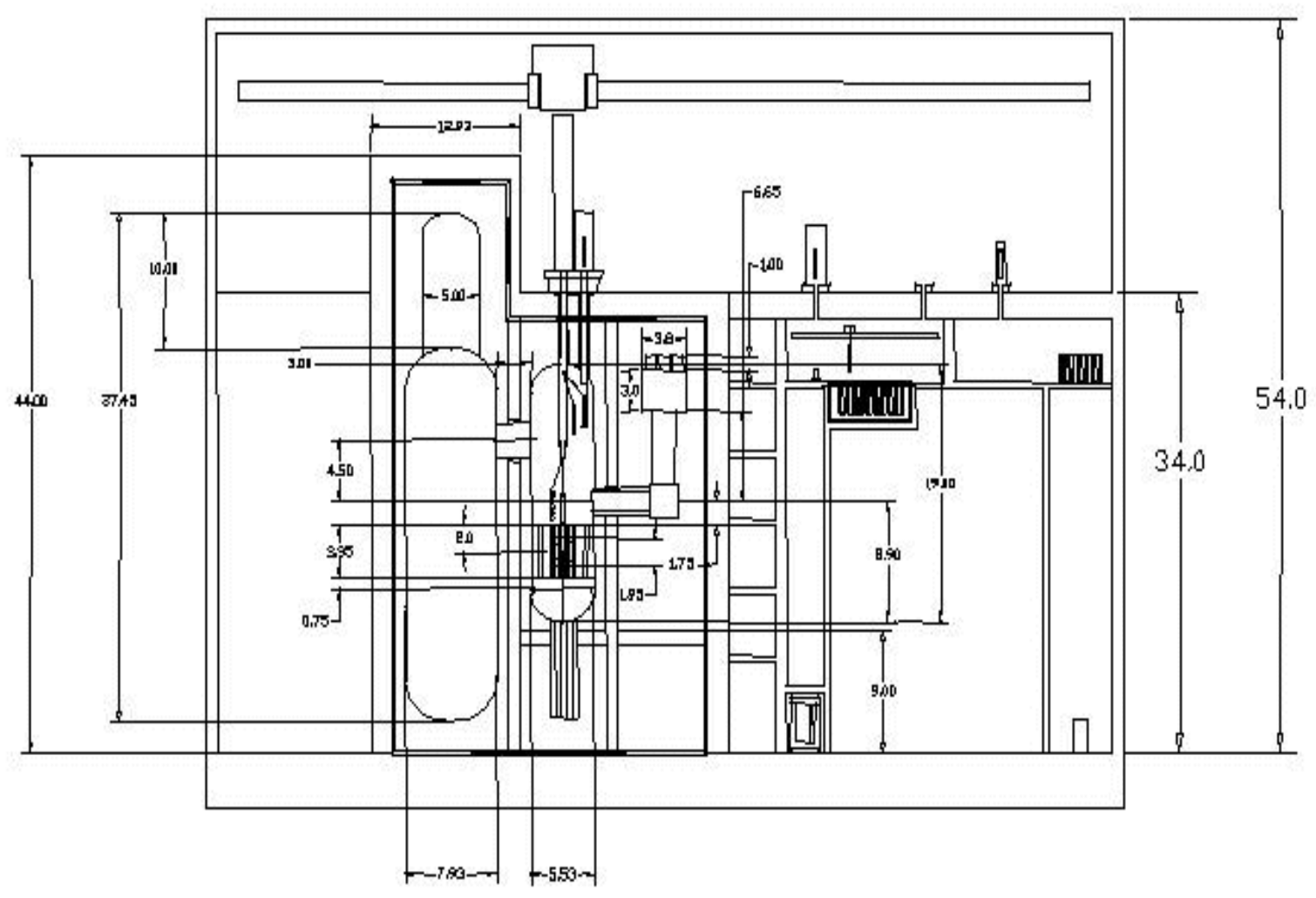

Figure 6. GFR system layout.

\subsection{Materials}

The fast spectrum (high fluence) and high temperatures expected in the reference GFR will require special materials; particularly for in-core applications. Table 2 gives the reference requirements for in-core and fuel matrix materials. 
Table 2. GFR fuel matrix and structural material reference requirements.

\begin{tabular}{|l|l|}
\hline \multicolumn{1}{|c|}{ Requirement } & \multicolumn{1}{|c|}{ Reference Value } \\
\hline $\begin{array}{l}\text { Melting/decomposition } \\
\text { temperature }\end{array}$ & $>2000^{\circ} \mathrm{C}$ \\
\hline $\begin{array}{l}\text { Radiation induced } \\
\text { swelling }\end{array}$ & $<2 \%$ over service life \\
\hline Fracture toughness & $>12 \mathrm{MPa} \mathrm{m}^{1 / 2}$ \\
\hline Thermal conductivity & $>10 \mathrm{~W} / \mathrm{mK}^{1 / 2}$ \\
\hline Neutronic properties & $\begin{array}{l}\text { Materials allow low core heavy metal } \\
\text { inventory and maintain good safety } \\
\text { parameters }\end{array}$ \\
\hline
\end{tabular}

Based on the requirements, only ceramics can meet the reference values. Those that appear to meet these requirements are $\mathrm{SiC}, \mathrm{ZrC}, \mathrm{TiC}, \mathrm{ZrN}$, and $\mathrm{TiN}$. Certain metallic alloys are also considered for out of core applications, including alloys T122, $800 \mathrm{H}$, and certain ODS metals. Current work is assessing the radiation stability of these materials, through neutron irradiations in ATR of the ceramic and metallic candidates, and heavy ion $(\mathrm{Kr})$ irradiations of the ceramic candidates. The neutron irradiations are not complete, and will attain a dose of approximately 10 dpa. However, several of the ceramic candidates have been heavy ion irradiated (up to $70 \mathrm{dpa}$ ), where preliminary analyses show significant swelling of the Zr-based ceramics.

\subsection{Energy Conversion}

The reference plant is a single shaft machine with the turbine, a low-pressure compressor, a highpressure compressor, and the electric generator all mechanically linked together. The coolant is helium gas and circulates through a direct cycle circuit as shown in Figure 7. The inlet to each compressor is cooled by a heat exchanger that is assumed to be cooled on its secondary side by liquid water that enters at the temperature of the environment. The secondary side is pressurized to remain single phase during all transients. The gas volumes and the mass of the structures associated with each of the primary system components are shown in Table 3. 


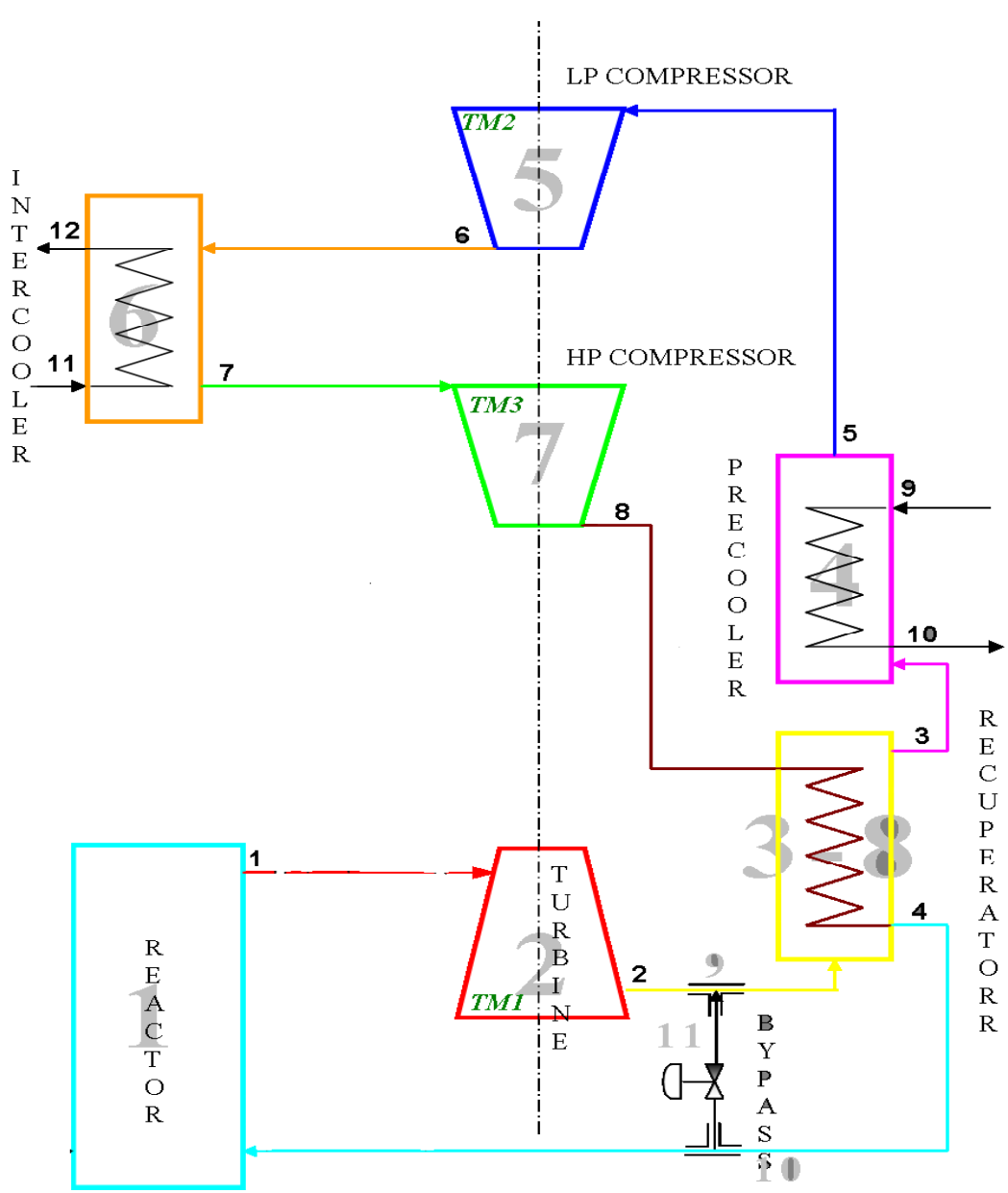

Figure 7. Schematic of equipment configuration during operation with hot bypass of turbine.

Table 3. Gas volumes and component masses.

\begin{tabular}{|c|c|c|}
\hline Component & Gas Volume $\left(\mathrm{m}^{3}\right)$ & Structure Mass (MTonne) \\
\hline Turbine & 38 & 245 \\
\hline Recuperator-Hot Side & 95 & 217 \\
\hline Recuperator-Cold Side & 95 & 217 \\
\hline Precooler & 177 & 199 \\
\hline Intercooler & 174 & 211 \\
\hline High Pressure Compressor & 38 & 245 \\
\hline Low Pressure Compressor & 83 & 248 \\
\hline
\end{tabular}

\subsection{Fuels and Fuel Cycle}

While the fuels and fuel cycle work falls under the purview of AFCI, it is reported here due to its importance in the design of the GFR. Current fuel designs are based on dispersion fuels (either as fibers/small "pellets" or particles) in an inert plate/block type matrix, or solid solution fuel clad in a refractory ceramic (e.g., $\mathrm{SiC} / \mathrm{SiC}$ composites). The reference fuels chosen for the GFR 
are mixed (i.e., $\mathrm{U}+\mathrm{Pu}+\mathrm{MA}$ ) nitrides and carbides for their high heavy metal density, high conductivity, and minimal impact on neutron spectrum (although limited irradiation data exists). Most of the effort and work is focused on development of dispersion particle fuel, and fiber/stick/pellet fuels. Figure 8 is a graphical representation of the fuel types being considered.

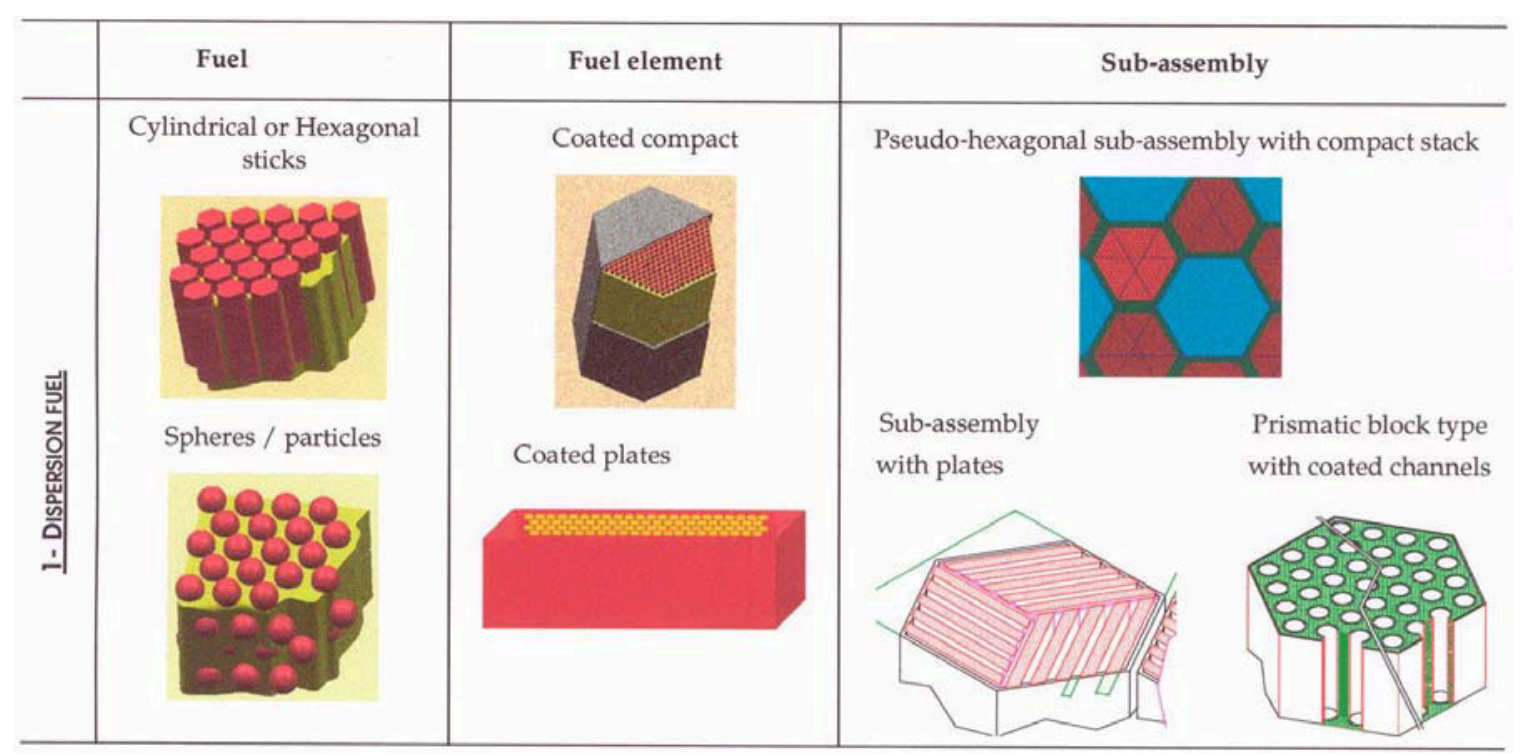

Figure 8. Dispersion fuel concepts.

Fuel particles have been successfully fabricated at ANL-W using a Rotating Electrode Process (REP) atomization. The process uses a low voltage, high current arc to melt a feedstock material, where droplets are flung from the rotating electrode (see Figure 9).

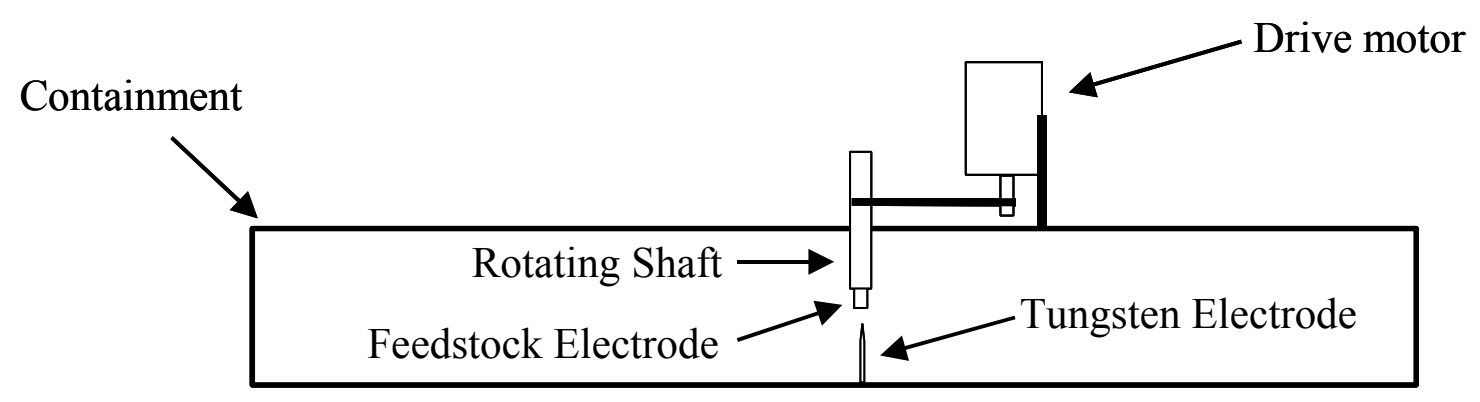

Figure 9. REP atomizer.

The droplet size depends on the rotational speed of the electrode, where the droplets are solidified into spheres. The feedstock is uranium carbide (UC), and is fabricated using simple resistance heating through the following reaction:

$$
\mathrm{U}+\mathrm{C} \rightarrow \mathrm{UC}
$$

The heating time is $\sim 30 \mathrm{~s}$, and total production time $<1$ hour. Fabricated UC particles can be seen in Figure 10. 

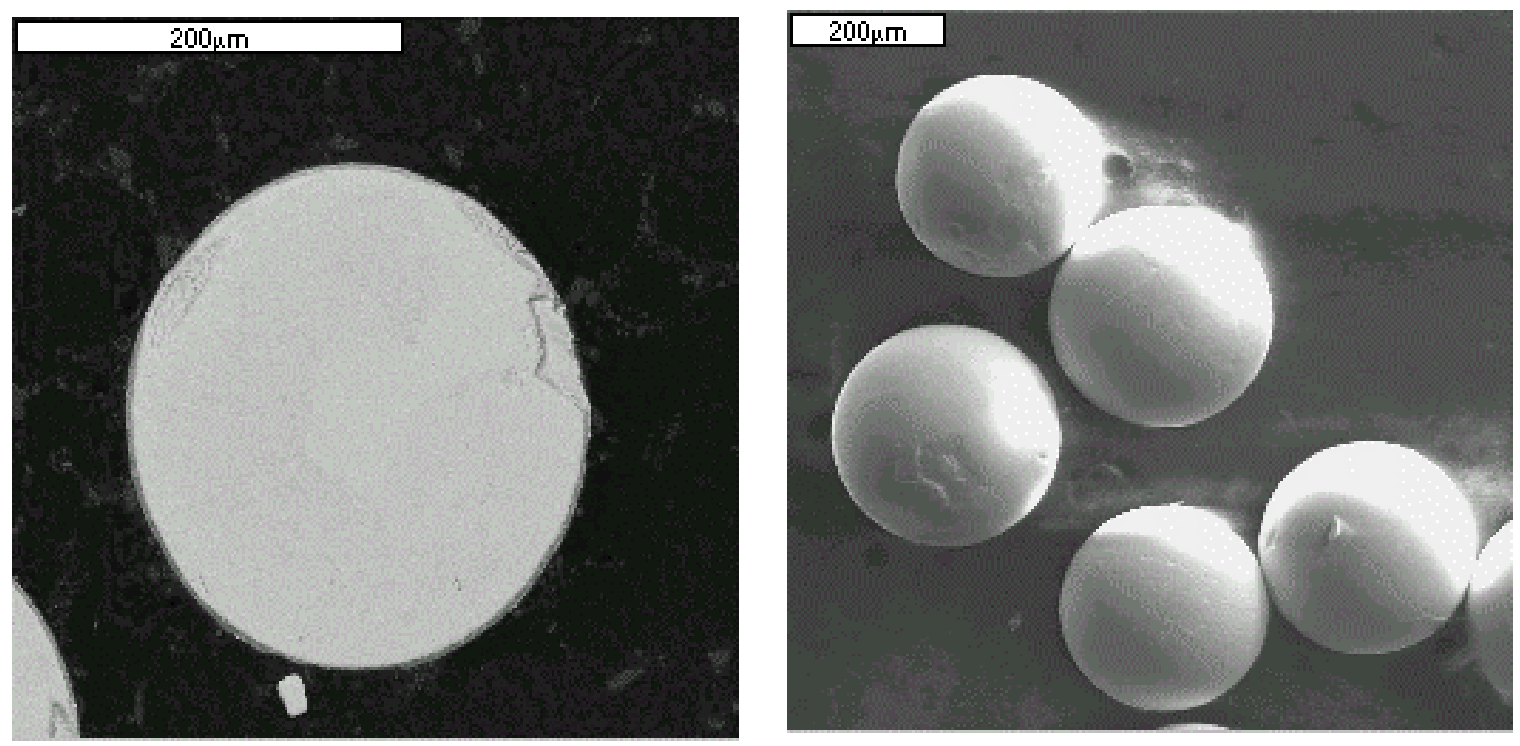

Figure 10. UC particles fabricated using the REP atomizer.

Advantages to using this process include a high yield and no liquid waste, but some shrinkage pores are evident.

A key issue for the particle fuel concerns the development of special coatings; particularly the use of non-halide precursors, and the development of low-density ceramic buffer layers. Through the previous I-NERI program, ORNL has been successful in coating surrogate particles, with a $50 \%$ dense $\mathrm{SiC}$ buffer layer, and dense $(90 \%)$ SiC seal coat using non-halide precursors. Figures 11 and 12 are micrographs of the particles and coatings.

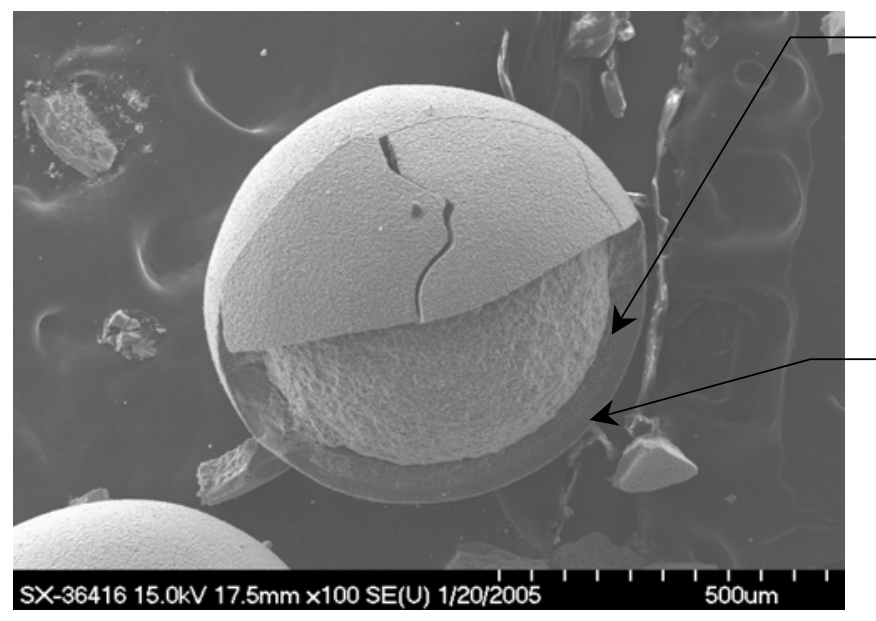

\section{SiC Buffer Coating \\ -? $50 \%$ dense \\ - By FBCVD from non-halide precursors (methylsilane)}

\section{SiC Seal Coating}

- ? $90 \%$ dense

- By FBCVD from non-halide precursors (methylsilane)

Figure 11. Successfully coated particle. 


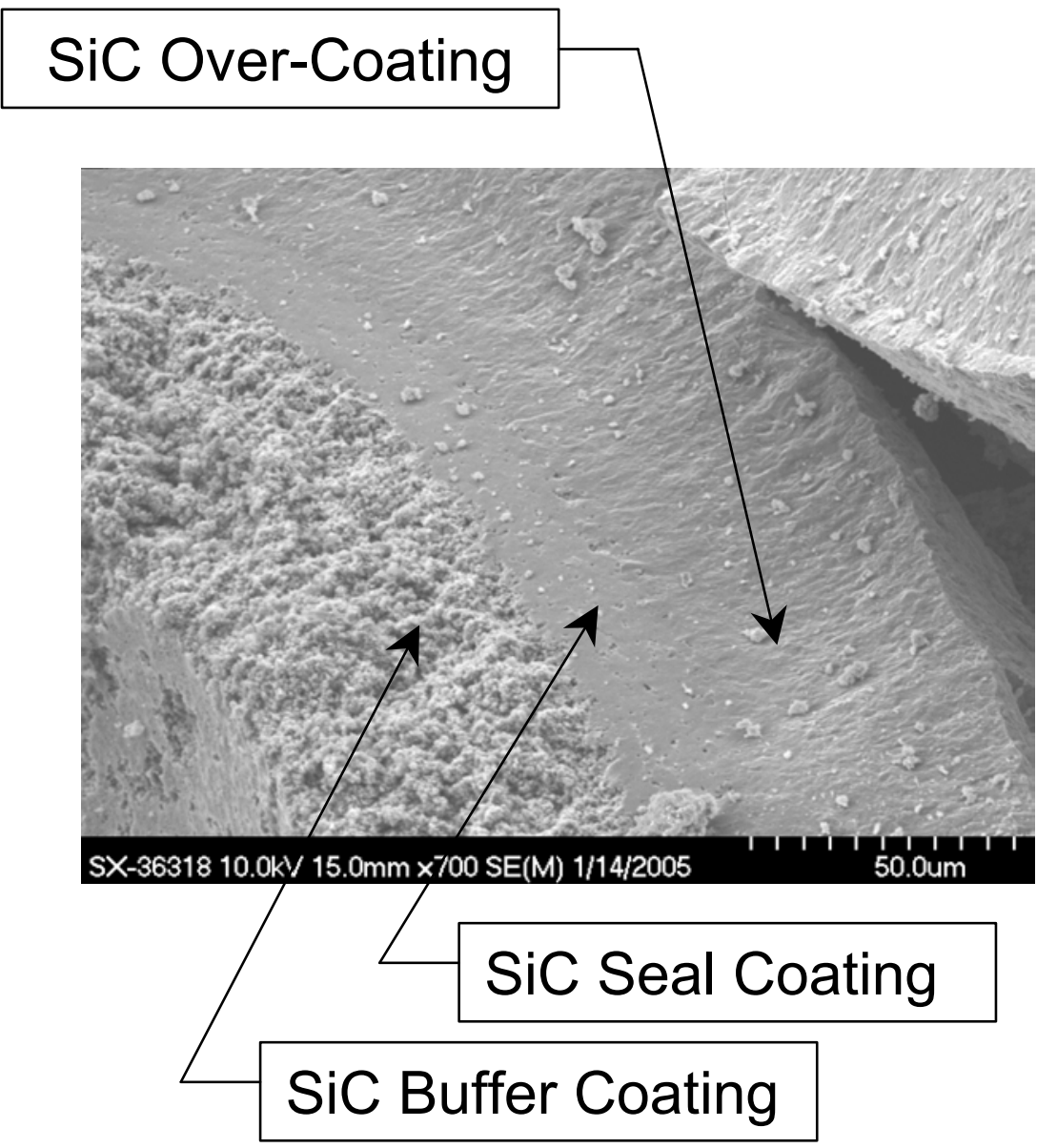

Figure 12. Micrograph of SiC coatings.

The next step includes the fabrication of the matrix material. Current studies are focusing on using infiltration/reaction bonding to make $\mathrm{SiC}$ with imbedded fuel particles.

\section{Current Status of the Optional Designs}

With the exception of the applicable fuels and materials work for the reference design, no funding had been allocated specifically for the optional GFR designs last fiscal year (FY04), nor for the current fiscal year (FY05). However, other work being performed outside of the Generation IV GFR scope is applicable, and is given in subsequent sections.

\subsection{System Design and Safety}

For the indirect cycle design, the primary system is the same as that being considered for the reference design. No further design and safety studies are being performed at this time for the indirect cycle system.

Development of the direct $\mathrm{S}-\mathrm{CO}_{2}$ cycle system was not performed under this project, but was funded by an LDRD at the INEEL, where MIT contributed to the research. Specifically for the core design, use of the reference design fuel featuring $\mathrm{SiC}$ as the fuel matrix allows for a small $(<\$ 1)$ to negative depressurization reactivity. In addition, use of $\mathrm{CO}_{2}$ as a coolant allows for 
excellent natural convective cooling during accident conditions due to the relatively high mass of the gas (compared to helium).

Further research on the direct $\mathrm{S}-\mathrm{CO}_{2}$ system will be continued later in FY05 under a U-NERI awarded to MIT.

\subsection{Materials}

Those materials being developed for the reference design will be utilized for both the indirect and direct $\mathrm{S}-\mathrm{CO}_{2}$ designs. Material compatibility issues with $\mathrm{S}-\mathrm{CO}_{2}$ were studied under the LDRD mentioned previously, and will be completed during the summer of 2005.

\subsection{Energy Conversion}

The $\mathrm{S}-\mathrm{CO}_{2}$ power conversion cycle is currently being studied under the Energy Conversion crosscut area, and will not be specified here.

\subsection{Fuels and Fuel Cycle}

No specific fuel or fuel cycle work is being done for the indirect and direct $\mathrm{S}-\mathrm{CO}_{2}$ reactors. Current designs include the GFR reference design fuels, and more traditional metal clad pins with solid solution fuel for the direct $\mathrm{S}-\mathrm{CO}_{2}$ reactor.

\section{Future Work}

Work will continue on the reference design as discussed in previous sections. Work on the direct cycle $\mathrm{S}-\mathrm{CO}_{2}$ option will begin later this fiscal year under the U-NERI program.

\subsection{Path Forward for a Down Selection}

Currently there exists a conflict between the timing of a fast reactor down select within the U.S. (to be made in 2010), the current budget allocations for the GFR to meet this milestone, and the decision of whether to further pursue the GFR based on the viability research being done under the GIF (to be made in 2012, and perhaps later based on the current funding profiles). Given these constraints, the earliest an informed decision could be made on the viability of the GFR would be 2012 . 